\title{
Modified spiht algorithm for quincunx wavelet image coding
}

\author{
Benyahia Ismahane, Bassou Abdesselam, Allaoui Chems El houda, Beladgham Mohammed \\ Department of Electrical Engineering, Tahri Mohammed University-Bechar, Algeria
}

\begin{tabular}{ll}
\hline Article Info & ABSTRACT \\
\cline { 2 - 3 } Article history: & $\begin{array}{l}\text { In this paper, an image compression method based on the Quincunx algorithm } \\
\text { coupled with the modified SPIHT encoder (called SPIHT-Z) is presented. The }\end{array}$ \\
$\begin{array}{l}\text { Received Jan 1, 2019 } \\
\text { Revised Feb 16, 2019 }\end{array}$ & $\begin{array}{l}\text { SPIHT-Z encoder (coupled with quincunx transform) provides better } \\
\text { compression results compared with two other algorithms: conventional } \\
\text { Accepted Mar 15, } 2019\end{array}$ \\
$\begin{array}{l}\text { wavelet and quincunx both coupled with the SPIHT encoder. The obtained } \\
\text { results, using the algorithm that applies (Quincunx with SPIHT-Z) are } \\
\text { Keyaluated by image quality evaluation parameters (PSNR, MSSIM, and VIF). } \\
\text { The compression results on twenty test images showed that the proposed } \\
\text { Evaluation Parameters } \\
\text { Image compression }\end{array}$ & $\begin{array}{l}\text { algorithm achieved better levels of the image evaluation parameters at low } \\
\text { bit rates. }\end{array}$
\end{tabular}

Qumpression

Quincunx

SPIHT

SPIHT-Z

\section{Corresponding Author:}

Benyahia Ismahane,

Department of Electrical Engineering,

Tahri Mohammed University-Bechar, Algeria.

Email: ismahanelv4@gmail.com

\section{INTRODUCTION}

Compression consists of reducing the physical size of an information block (the number of bits) needed to represent the characteristics of an image (eliminating redundancies) to enable the reduction of storage cost and the rapid transmission of data [1]. The current methods of compression of still and moving images (video) are based on the wavelet transform; this latter had a huge success in the field of image processing such as image compression due to its ability to compress the image energy on a small number of coefficients allowing efficient coding of the image [2,3].

Traditional multiresolution decompositions appear to be a restricted and limited category [4]. In order to overcome this problem, new transforms better adapted to the representation of the images have been proposed. In this work, a new method based on the quincunx wavelet transform coupled with the SPIHT-Z progressive encoder had introduced to compress different types of images such as medical, satellite, and natural images in order to prove the effectiveness of the proposed method for compression with low bit rates..

\section{QUINCUNX TRANSFORM}

The dyadic separable analysis requires three families of wavelets, this is sometimes considered as a disadvantage, on the other hand the expansion factor between two successive scales is 4 , which may seem high. It is possible to remedy these two problems, but on the cost of the loss of the separability of the filters and therefore of a slightly higher algorithmic complexity. An analysis has been particularly studied and found practical applications; it is the so-called "quincunx" analysis. Figure 1 illustrates this type of decomposition [5]. We will see that the expansion factor is only 2 between two successive resolutions and only one family of wavelets is necessary [6].

In this case, the expansion matrix equals $M=\left[\begin{array}{rr}1 & 1 \\ 1 & -1\end{array}\right]$ 
The transformation of the mesh (lattice) is done according to the following diagram:

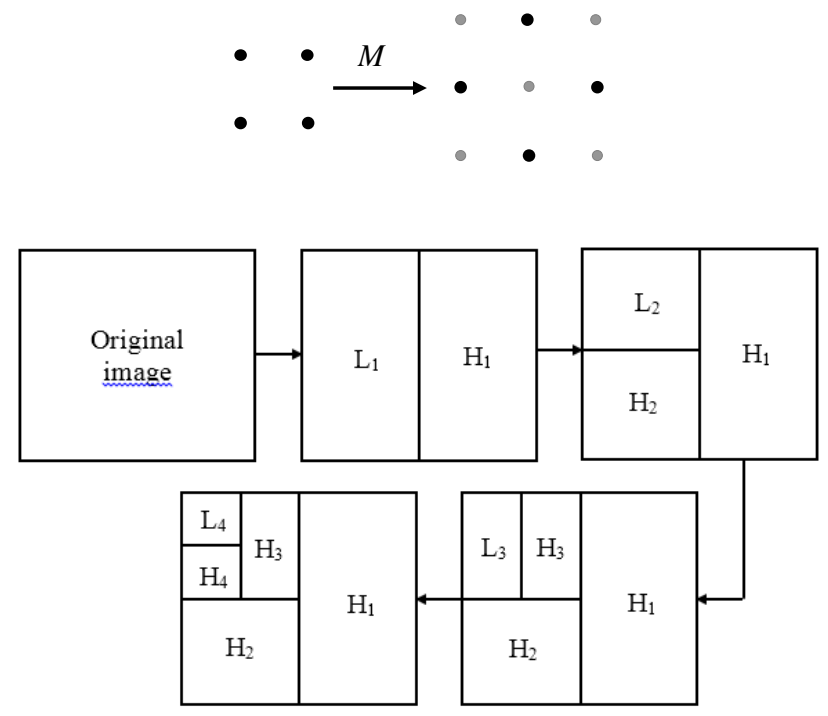

Figure 1. Quincunx wavelet decomposition

This matrix generates a quincunx lattice in two dimensions. The column vectors of this matrix form a base of this lattice. The volume of the associated elementary cell is 2 Figure 2. This same lattice also comes from the matrix $[7,8]$

$$
M^{\prime}=\left[\begin{array}{rr}
1 & -1 \\
1 & 1
\end{array}\right]
$$

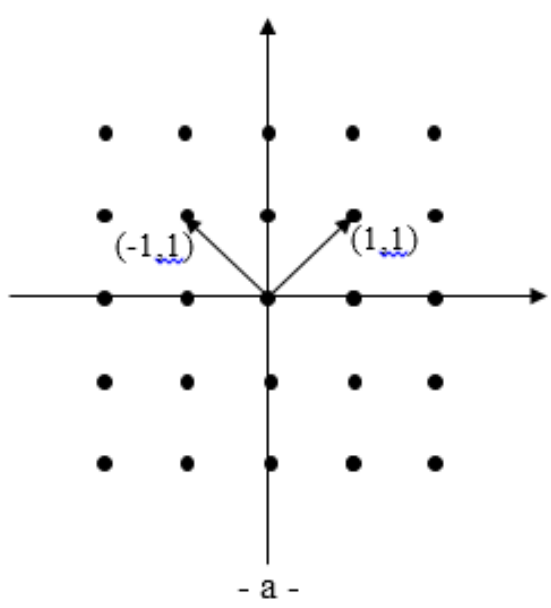

Quincunx grid

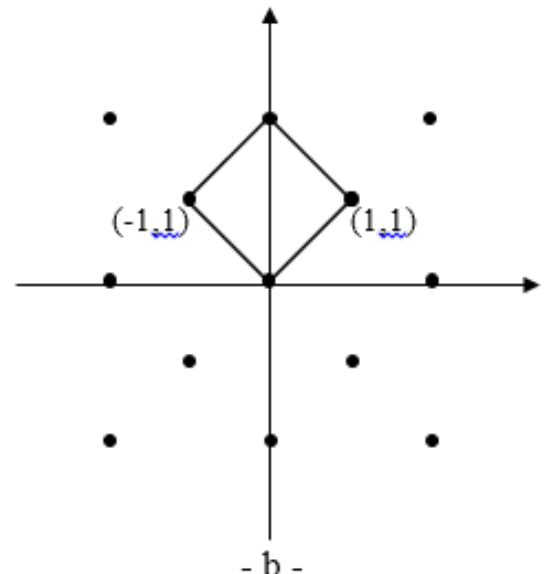

Elementary cell

Figure 2. Example of the quincunx grid and the elementary cell

It can be seen that the dilation pitch is $\sqrt{2}$ on each direction and the geometry of the mesh obtained justifies the name given to this multiresolution analysis [9]. 
As the quincunx sampling reduces the image size by a factor of 2 , then the associated filter bank has two channels Figure 3. The low-pass filter $\tilde{H}$ reduces the resolution by a factor of $\sqrt{2}$. The coefficients of the wavelet correspond to the output of the high- filter $\tilde{G}$

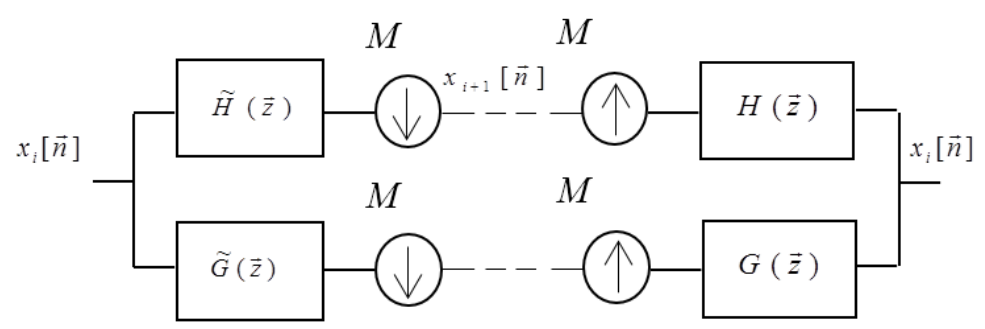

Figure 3. The perfect reconstruction filter bank with the quincunx sampling

Where $H$ and $G$ (respectively $\tilde{H}$ and $\tilde{G}$ ) are the transfer functions of the synthesis filters (respectively analysis). These filters correspond to the bases of decomposition and reconstruction of the wavelets [10]. The perfect reconstruction tells us that there is no loss of information during the iterations of analysis. In our case the analysis will be orthogonal, i.e., the analysis and synthesis filters are the same.

The underlying quincunx wavelet is given by

$$
\psi_{\alpha}(\vec{x})=\sqrt{2} \sum_{\vec{n} \in Z^{2}} g_{\alpha}[\vec{n}] \phi_{\alpha}(M \vec{x}-\vec{n})
$$

Where $g_{\alpha}[\vec{n}]$ is the spatial version of the filter $G_{\alpha}[\vec{\omega}]$.

The advantage of this approach is that filters for small values of $\alpha$ are almost isotropic (Figure.4), that is, the coefficients of the obtained wavelet transform have no preferential orientation, and this reflects the quality of the analysis [11].

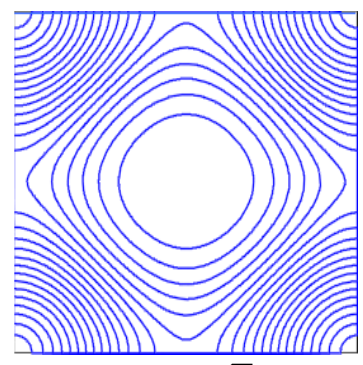

(a) $\alpha=\sqrt{2}$

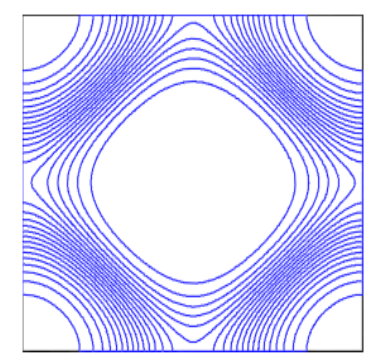

(b) $\alpha=\pi$

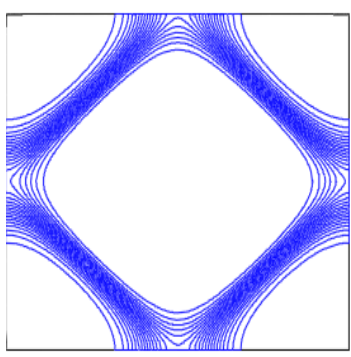

(c) $\alpha=10$

Figure 4. The perfect The isotropy of the filter $H_{\alpha}=\left(e^{j \vec{\omega}}\right)$ for different values of the order parameter $\alpha$

\section{THE SPIHT CODING ALGORITHM}

\subsection{The classic SPIHT algorithm}

The SPIHT algorithm (Set Partitioning In Hierarchical Trees) [12] performs a recursive partitioning of the tree so as to determine the position of the significant coefficients in the progeny of the considered coefficient. It is based on the same concepts: progressive coding by bit plane and use of hierarchical dependencies between the coefficients of the different subbands. However, a new dependency protocol between the coefficients is defined. The coefficients of the lower frequency sub-band (LL3 in Figure 5) are grouped by four, and for each group, the offspring is as follows: One of the four coefficients (LL3 in Figure 5) 
does not allow descendants, while the other three have four descendants each. For the other subbands, each coefficient has four descendants [13]

Three sets of coordinates are used to present the new coding method :

a. $\quad \mathrm{D}(\mathrm{x}, \mathrm{y})$ : Set of all the descendants of the pixel $(\mathrm{x}, \mathrm{y})$.

b. $\quad \mathrm{O}(\mathrm{x}, \mathrm{y})$ : Set of coordinates of the direct descendants of the pixel $(\mathrm{x}, \mathrm{y})$.

c. $\quad \mathrm{L}(\mathrm{x}, \mathrm{y})$ : Set defined as being $\mathrm{D}(\mathrm{x}, \mathrm{y})-\mathrm{O}(\mathrm{x}, \mathrm{y})$.

The SPIHT algorithm uses three lists of significant coefficients (LSP), insignificant coefficients (LIP), and insignificant sets (LIS). The entries for each of the lists are the (x,y) coordinates in the image matrix, which represent individual pixels in the case of LIP and LSP lists, and the set of D(x,y) or L(x,y) descendants in the case of the LIS list [14].

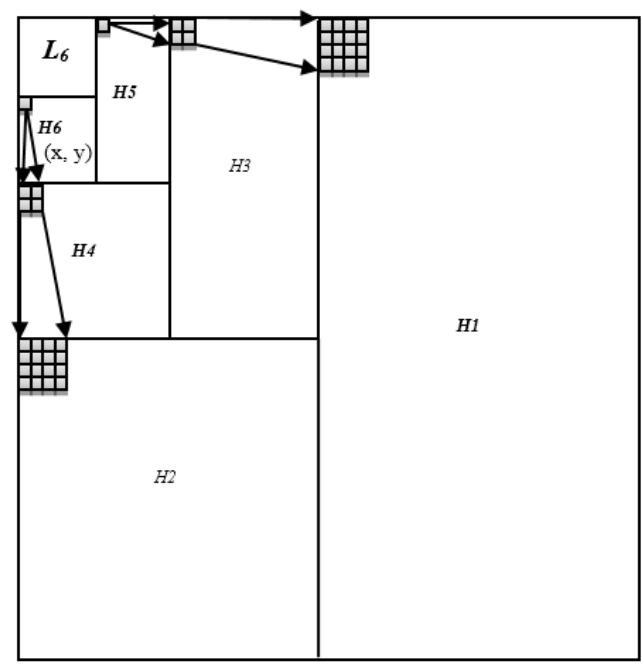

Figure 5. Repartition image used by SPIHT algorithm

\subsection{The modified SPIHT algorithm (SPIHT-Z)}

Figure 6 illustrates the tree of the SPIHT-Z algorithm according to the quincunx decomposition of the image. The representation of the spatial tree of the SPIHT-Z is as follow: The coefficient ( $x, y)$ of the subband (H6) points to two sons (a set of $2 \times 1$ adjacent pixels) ( $x-L x, y+L y)$ and ( $x-L x+1, y+L y)$. The coefficients of the subband (H5) point to four descendants ( $x-L x, y+L y),(x-L x+1, y+L y),(x+L x, y-L y+1)$ and $(x+L x+1, y-$ $\mathrm{Ly})$, of coefficients of the subband (H4) and so on until the last subband H1 as shown in Figure 6.

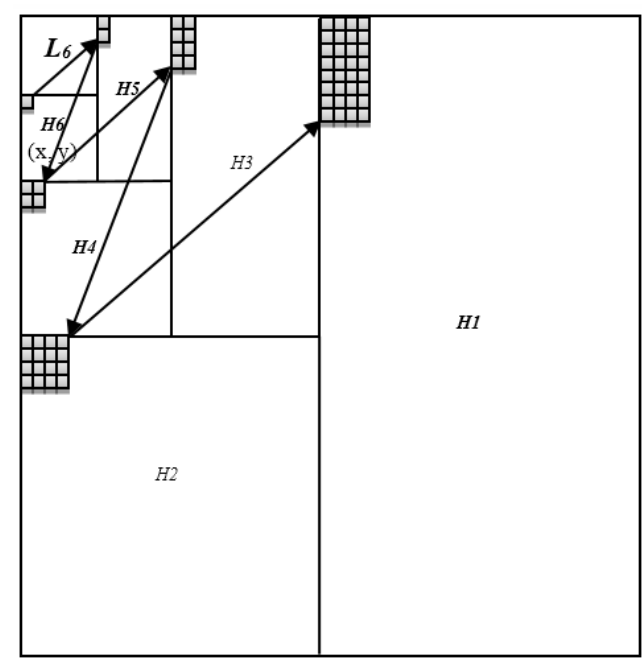

Figure 6. Repartition image used by SPIHT-Z algorithm 
The SPIHT-Z algorithm can be summarized as follow

a. If the number $i$ of the sub-band $\left(H_{i}\right)$ is an even integer, the pixel $(x, y)$ points to two pixels of the subband $\left(H_{i-1}\right)$ having the coordinates $\left(x-L_{x}, y+L_{y}\right)$ and $\left(x-L_{x}+1, y+L_{y}\right)$ as shown in Figure 7.(a).

b. If the number of iterations $i$ of the subband $\left(H_{i}\right)$ is an odd integer, the pixel $(x, y)$ of the sub-band $\left(H_{i}\right)$ points to two pixels of the subband $\left(H_{i-1}\right)$ having the coordinates $\left(x+L_{x}, y-L_{y}+1\right)$ and $\left(x+L_{x}+\right.$ $1, y-L_{y}$ ) as shown in Figure 7.(b).

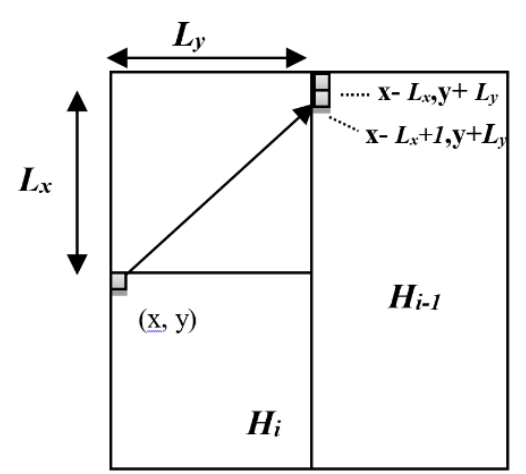

(a)

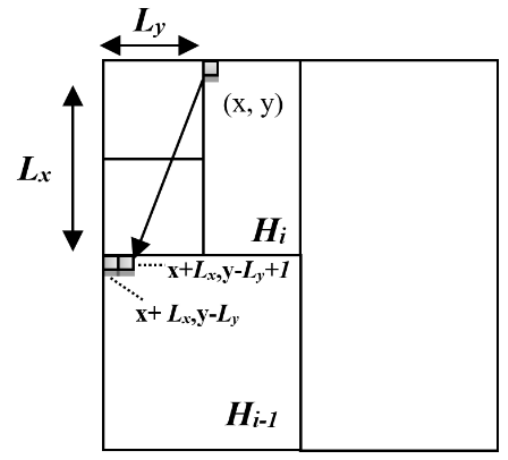

(b)

Figure 7. SPIHT-Z algorithm pattern

This pattern which starts increasing from subband (H_i) to higher subband (H_(i-3)) draws a "Z" symbol which gives the appellation "SPIHT-Z" as shown in Figure 5. As the SPIHT algorithm, the SPIHT-Z considers three lists: LSP, LIP and LIS.

\section{QUALITY EVALUATION PARAMETERS}

The commonly parameter used in image compression is the mean square error MSE. This variable (error) is defined by the mean square between the pixel $(i, j)$ of the original image $I(i, j)$, and the pixel $(i, j)$ of the reconstructed image $\hat{I}(i, j)[15,16]$.

$$
M S E=\frac{1}{M \cdot N} \cdot \sum_{m=0}^{M-1} \sum_{n=0}^{N-1}[I(i, j)-\hat{I}(i, j)]^{2}
$$

The peak signal to noise ratio $[17,18]$

$$
P S N R=10 \cdot \log _{10} \frac{\left(2^{R}-1\right)^{2}}{M S E}[d B]
$$

We then evaluate a new paradigm for assessing the quality of medical images, the similarity index compares the brightness, contrast, and structure between each pair of vectors, where the index of structural similarity (SSIM) between two signals $\mathrm{x}$ and $\mathrm{y}$ is given by the following expression.

$$
\operatorname{SSIM}(x, y)=l(x, y) c(x, y) s(x, y)
$$
the formula

Finally, for the purpose, we need a single global measure of overall image quality that is given by

$$
\operatorname{MSSIM}(I, \hat{I})=\frac{1}{M} \sum_{i=1}^{M} \operatorname{SSIM}\left(I_{i}, \hat{I}_{i}\right)
$$


$M$ is the total number of local windows in the image. The values MSSIM exhibit greater consistency with the visual quality. [19, 20]

The Visual Information fidelity parameter (VIF) quantifies Shannon information that is shared between the reference and distorted images with respect to the information contained in the reference image itself. VIF test is then evaluated as [21-23]

$$
V I F=\frac{\sum_{j}^{M} I\left(C^{j} ; F^{j} \mid s^{j}\right)}{\sum_{j}^{M} I\left(C^{j} ; E^{j} \mid s^{j}\right)}
$$

Where, $I(X ; Y \mid Z)$ is the conditional mutual information between $X$ and $Y$, conditioned to $Z ; \mathrm{j}$ s is a realization of $\mathrm{S} \mathrm{j}$ for a particlar image, the index $\mathrm{j}$ runs through all sub-bands in the decomposed image.

\section{RESULT}

In this paper, the quincunx wavelet transform (QWT) coupled with the SPIHT and SPIHT-Z coders had applied. a filter order parameter $\alpha=3$ and an iteration number $\lambda=6$ for wavelet quincunx decomposition. Tables 1, 2 and 3, given in appendises A, B and C, show respectively the compression results of 20 medical images, 20 satellite images and 20 natural images of size $512 \times 512$. All considered images are 255 gray-level. the bit rate varies from 0.1 to $0.5 \mathrm{bpp}$, and the image evaluation parameters PSNR, MSSIM and VIF are used to compare QWT CDF9/7 + SPIHT-Z, QWT CDF9/7 + SPIHT and DWT (with lifting structure [24-26]) CDF9/7 + SPIHT.

From these results, it can be noted that the proposed algorithm QWT CDF9/7 + SPIHT-Z gives better image compression quality compared to the other algorithms (QWT CDF9/7 + SPIHT, DWT (Lifting) CDF9/7 + SPIHT), and this can be observed in the important values of PSNR $=46.83, \mathrm{MSSIM}=0.98, \mathrm{VIF}=0.74$ for medical images; PSNR = 31.3, MSSIM = 0.81, VIF = 0.39 for satellite images; and PSNR = 37.77, MSSIM = $0.92, \mathrm{VIF}=0.55$ for natural images asb shown in Figure 11 .

In order to confirm these results, the averages of the evaluation parameters (PSNR, MSSIM, and VIF) of the 20 test images had calculated. Figures 8, 9 and 10 show the average curves of medical, satellite, and natural images. From these results, the proposed algorithm QWT CDF9 / $7+$ SPIHT-Z gives good image compression quality especially at low bit rates.
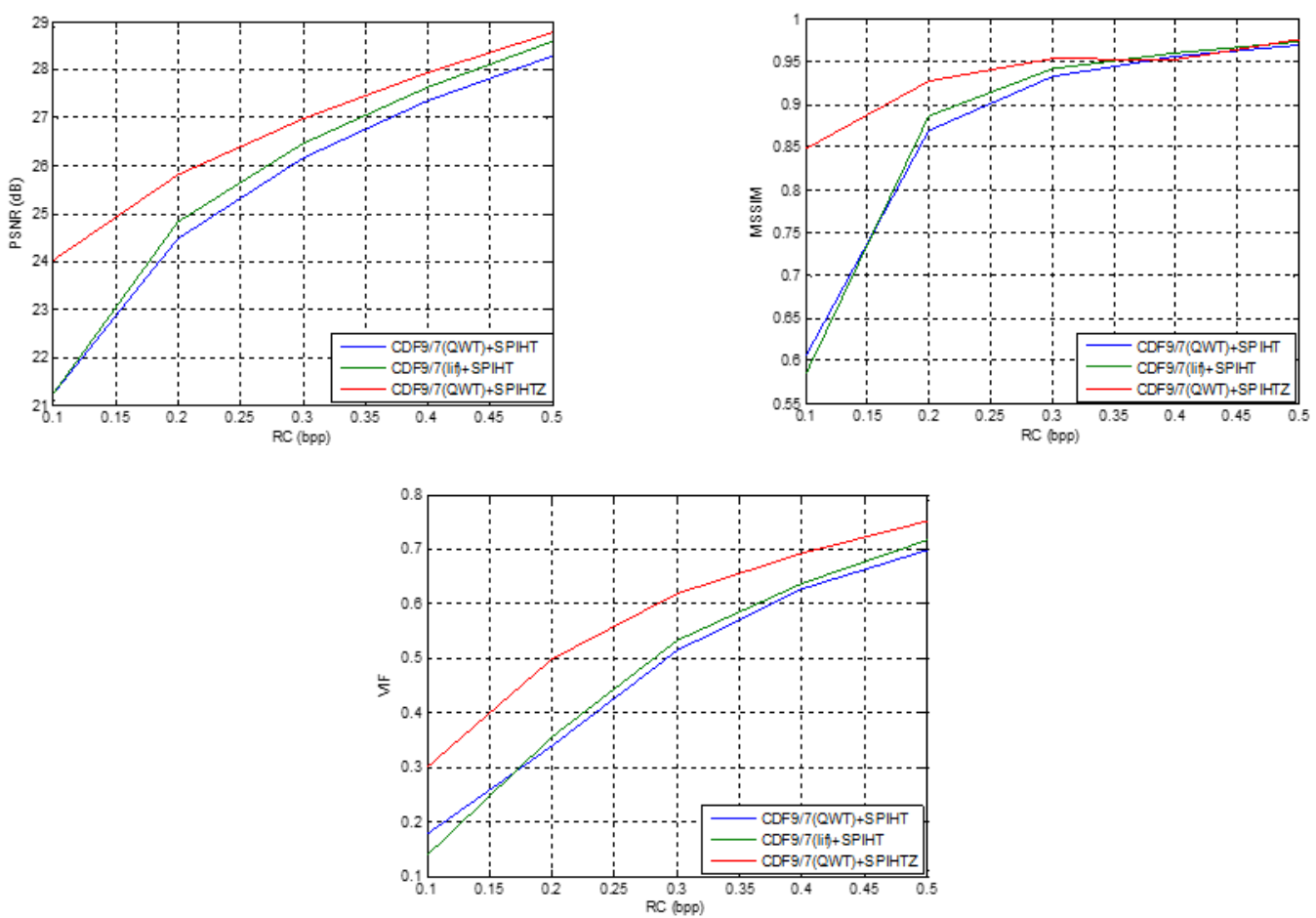

Figure 8. Variation of average PSNR, MSSIM and VIF (over 20 Medical images) 

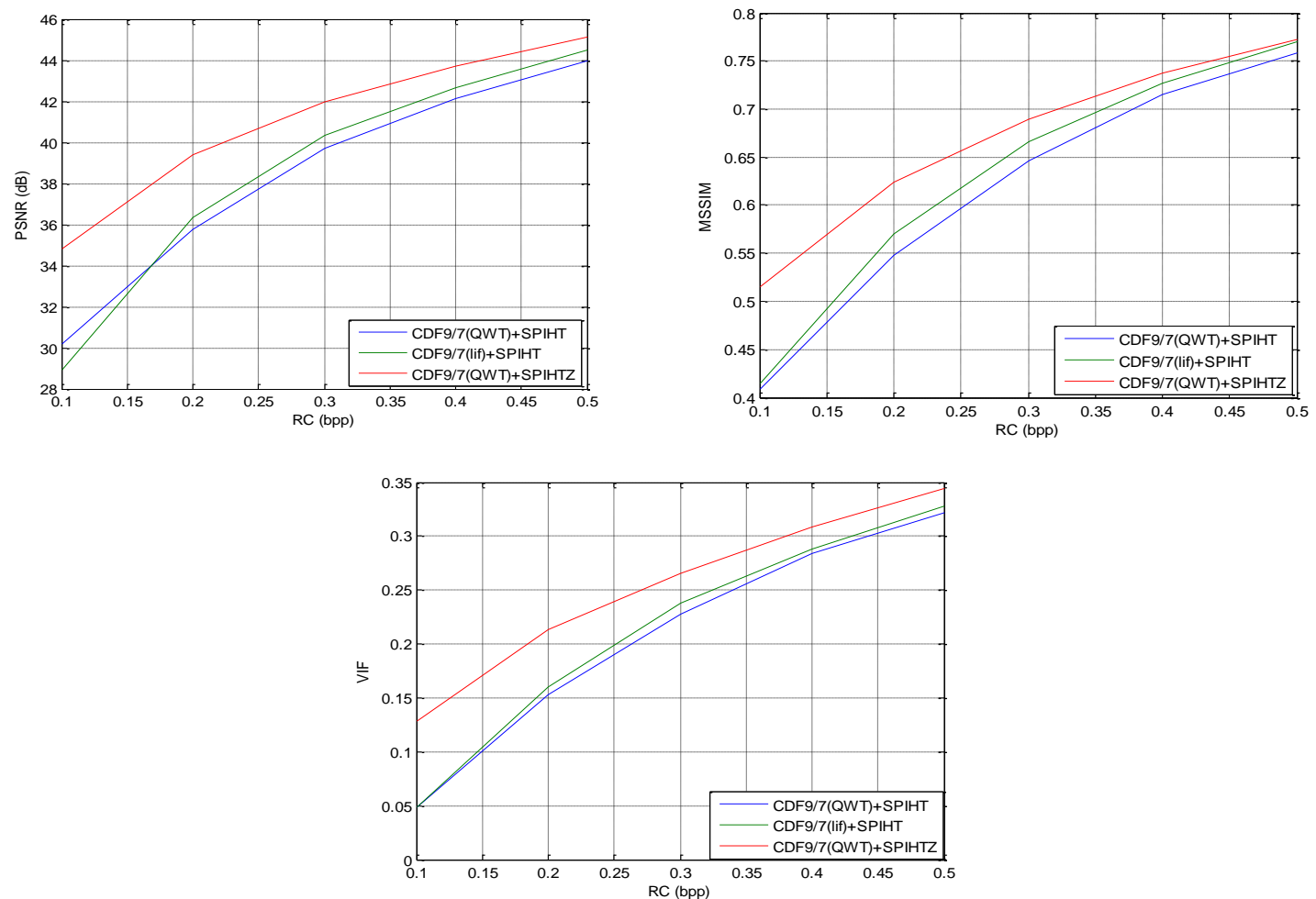

Figure 9. Variation of average PSNR, MSSIM and VIF (over 20 satellite Images)
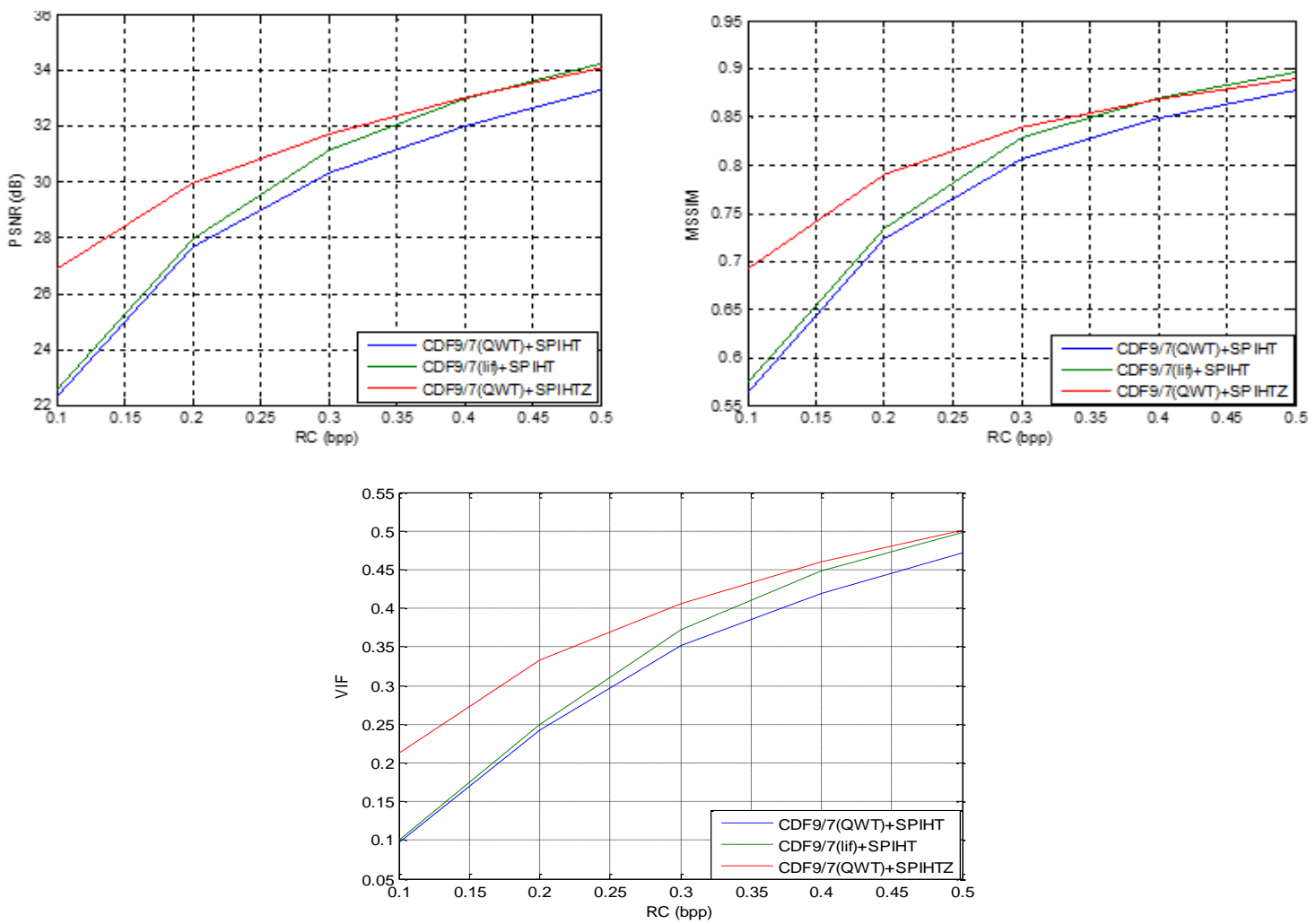

Figure 10. Variation of PSNR, MSSIM and VIF (over 20 natural Images) 


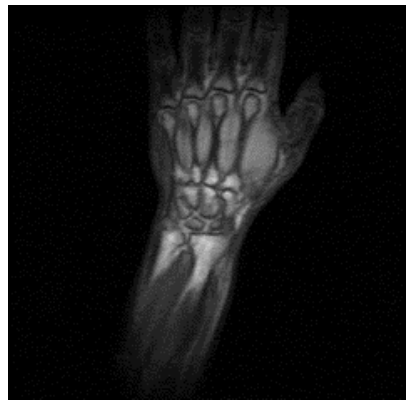

PSNR $=47.41 \mathrm{~dB}$, MSSIM $=0.98$ $\mathrm{VIF}=0.78$

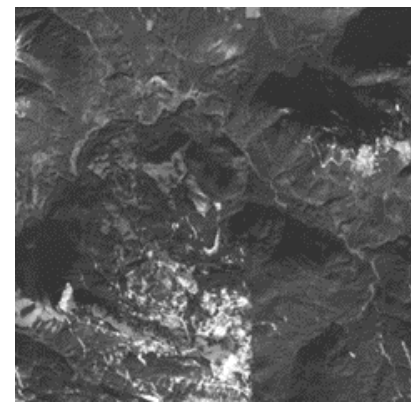

$\mathrm{PSNR}=31.3 \mathrm{~dB}, \mathrm{MSSIM}=0.81$ $\mathrm{VIF}=0.39$

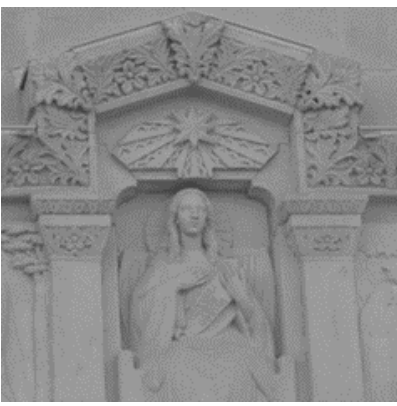

$\mathrm{PSNR}=37.77 \mathrm{~dB}, \mathrm{MSSIM}=0.92$, $\mathrm{VIF}=0.55$

Figure 11. Medical, satellite, and natural images compressed by CDF9/7(QWT) + SPIHT-Z

\section{CONCLUSION}

In this work, the efficiency of the quincunx wavelet transform QWT has been improved by introducing a modified SPIHT (SPIHT-Z) encoder that exploits the transition between all subbands of the quincunX wavelet transform (QWT). The obtained results are very satisfactory compared to other methods. The proposed algorithm is better adapted to low bit-rate image compression and especially in the medical field.

\section{ACKNOWLEDGEMENTS}

We want to thank very much the members and the directors of LTIT Laboratory of University of Bechar for their great availability, their encourangement, and their precious advice. I would also like to thank the editor and anonymous reviewers for their comments and suggestions.

\section{REFERENCES}

[1] G. Sadashivappa and K.V.S. Ananda Babu, "Performance analysis of Image Coding Using Wavelets," IJCSNS International Journal of Comp. Science and Network Security, Oct 2008.

[2] X. Delaunay., "Compression of satellite images by post-transformations in the field wavelets, Doctorat thesis, University of Toulouse, National Polytechnic Institute of Toulouse, France, 2008.

[3] M. Latfaoui and F. Bereksi Reguig, "Packets Wavelets and Stockwell Transform Analysis of Femoral Doppler Ultrasound Signals," IJECE (International Journal of Electrical and Computer Engineering), vol. 8(6), Dec 2018.

[4] Mohanad Najm Abdulwahed and Ali kamil Ahmed, "Underwater Image De-nosing using Discrete Wavelet Transform and Pre-whitening Filter," TELKOMNIKA, vol. 16(6), Dec 2018.

[5] Beldgham Mohammed., Construction d'une technique d'aide au diagnostic en imagerie médicale: application a la compression d'images, Doctorat Thesis, Tlemcen University, Algeria, 2012.

[6] D. Salomon., Data ompression, The Complete Reference, Fourth Edition, Springer Verlag London, 2007.

[7] V. Chappelier., Progressive coding of images by directed wavelet, Phd. Thesis, Rennes1 University, France, 2005.

[8] Y. Tanaka, M. Ikehara \& Q. N. Truong, "A New Combination of 1D and 2D Filter Banks for Effective Multiresolution Image Representation," IEEE International Conference on Image Processing, pp. 2820-2823, 2008.

[9] F. Manuela, VD. Dimitri \& U. Michael, "An Orthogonal Family of Quincunx Wavelets With Continuously Adjustable Order," IEEE Transactions on Image Processing, vol. 14(4), Apr 2005.

[10] V. D. Dimitri, B. Thierry \& U. Michael, "On the Multidimensional Extension of the Quincunx Subsampling Matrix", IEEE Signal Processing Letters, vol. 12(2), Feb 2005.

[11] Y. Chen, A.D. Michael \& L. Wu-Sheng, "Design of Optimal Quincunx Filter Banks for Image Coding," EURASIP Journal on Advances in Signal Processing, 2007.

[12] S.G. Miaou, S.T. Chen, \& S.N. Chao, "Wavelet-based lossy-to-lossless medical image compression using dynamic VQ and SPIHTcoding," Biomedical engineering-applications, basis \& communications, vol. 15(3), pp. 235-242, Dec 2003.

[13] I.boukli hacene.,"Compression d'images médicales par ondelettes de seconde génération, Doctorat Thesis, Tlemcen University, Algeria, 2014.

[14] C. Yen-Yu, and T. Shen-Chuan, "Embedded medical image compression Using DCT based subband decomposition and modified SPIHT data organization," Proceedings of the Fourth IEEE, (BIBE'04), 2004.

[15] K. Seshadrinathan, H. R. Sheikh, Z. Wang, \& A. C. Bovik, "Structural and Information Theoretic Approaches to Image Quality Assessment," Multi-Sensor image fusion and ITS Application, pp. 1-39, Jul 2005.

[16] T.Kavitha and K.Jayasankar, "Ideal Huffman Code for Lossless Image Compression for Ubiquitous Access, "IJEECS (Indonesian Journal of Electrical Engineering and Computer Science), vol. 12(2), Nov 2018. 
[17] P.Gregoire., Spatiotemporal wavelets and decompositions, application to scalable video coding, Doctoral Thesis, Specialty: Signal and Images, Ecole Nationale Supérieure des Télécommunications, Paris, June 15, 2006.

[18] Jonathan Taquet., Advanced Techniques for Medical Image Compression, PhD Thesis, National Institute for Research in Computer Science and Automation Center INRIA Rennes - Brittany Atlantic 2012.

[19] M.Beladgham, A.Bessaid, A.Taleb-Ahmed \& I. Boucli Hacene, "Medical Image Compression Using Quincunx Wavelets and SPIHT Coding," Journal of Electrical Engineering \& Technology, vol. 7(2), pp. 264-272, 2012.

[20] E. Dumic, S. Grgic, \& M. Grgic, "New image-quality measure based on wavelets," Journal of Electronic Imaging, vol. 19(1), pp. 011-018, Mar 2010.

[21] A. K. Moorthy, Z. Wang \& A. C. Bovik, Visual Perception and Quality Assessment, Chapiter 19 in Optical and Digital Image Processing, Wiley, 2010.

[22] Z. Wang and LI, "Information Content Weighting for Perceptual Image Quality Assessment," IEEE Transactions on Image Processing, vol. 20(5), pp. 1185-1198, May 2011.

[23] Ismahane Benyahia, Mohammed Beladgham \& Abdesselam Bassou," Evaluation of the Medical Image Compression using Wavelet Packet Transform and SPIHT Coding," IJECE (International Journal of Electrical and Computer Engineering), vol. 8(4), Aug 2018.

[24] Beladgham Mohammed, Habchi Yassine, Moulay Lakhdar Abdelmouneim, Bassou Abdesselam \& Taleb-Ahmed Abdelmalik, "New Contribution on Compression Color Images: Analysis and Synthesis for Telemedicine Applications," IJIEEB (I.J. Information Engineering and Electronic Business), vol. 2, pp. 28-34, 2014.

[25] Benyahia Ismahane., Utilisation du codage vidéo pour les applications médicale, Doctorat Thesis, Tahri mohamed Bechar University, Algerie, 2018.

[26] M. Beladgham, A.Bessaid, A. Moulay Lakhdar, M. Benaissa \& A.Bassou, "MRI image compression using biorthogonal CDF wavelet based on lifting scheme and SPIHT coding," CIGE'10, Proc. JRS, Vol. 2, pp. 225-232, Tahri Mohamed Bechar University, Nov 2010. 


\section{Appendix A}

Table 1. Variation of PSNR, MSSIM, VIF for Medical Images

| 㐫 శ్

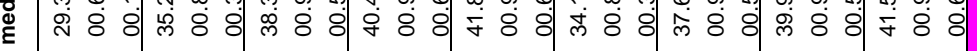

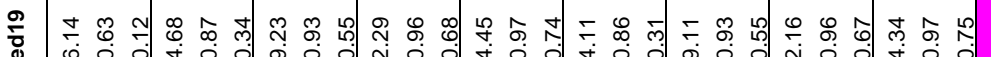
焉 品 只 荥 卢 焉 닐 豆 눌 党

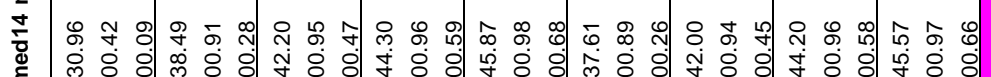

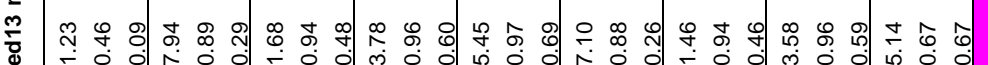

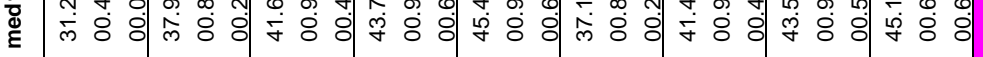

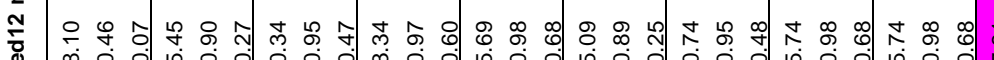

당

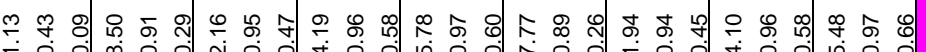

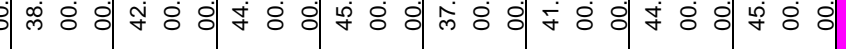
\%

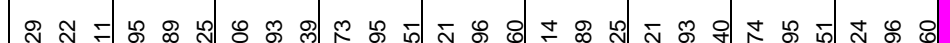
N 8 ட்

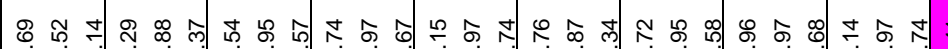
ஸे 8 i

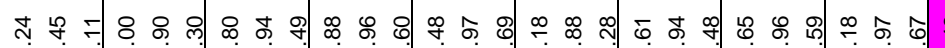

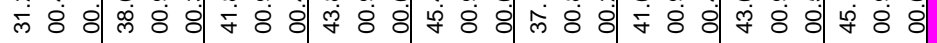

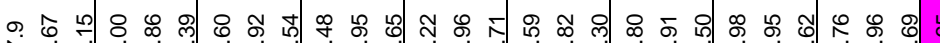
ง 8 : से 8 :

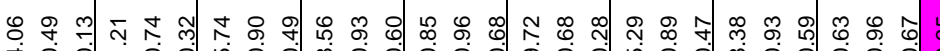

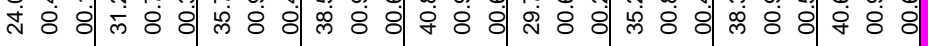

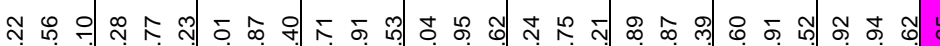

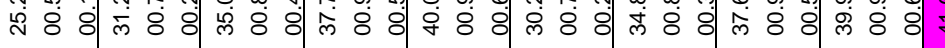

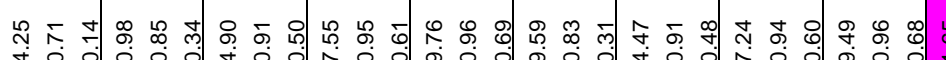
৯ 8 :

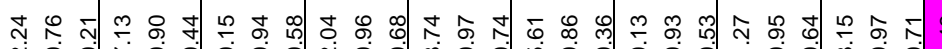
শ্ল
CDF9/7(QWT) +SPIHT

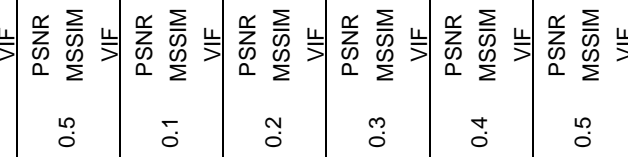

CDF9/7(QWT) +SPIHT-Z tน 舟 \&

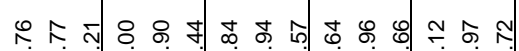
ल ८

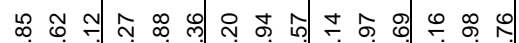

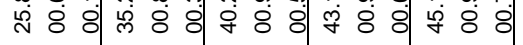
๓ 定 8 :

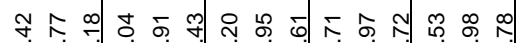
న \&

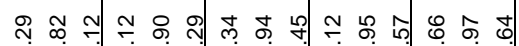
ஸे : 응의 ळ ल्ल 8 ठ

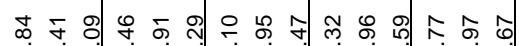
穴 :

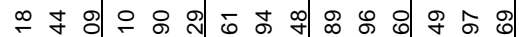
फं ठ்

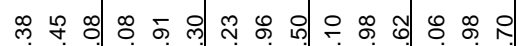
ஸे \& t

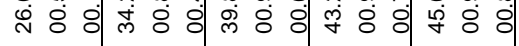

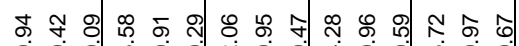

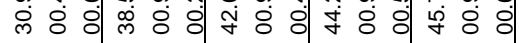
은 궁 \& ๙ 8 ठ

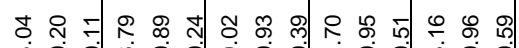

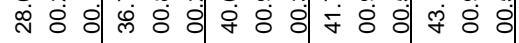

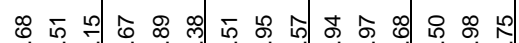
ஸ 8 டे

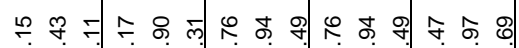

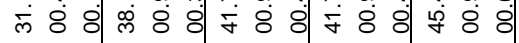

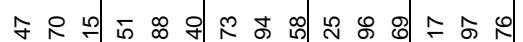

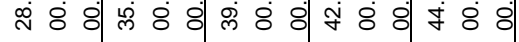

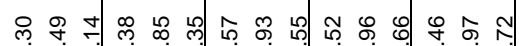

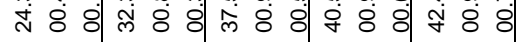

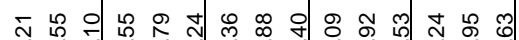

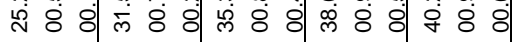

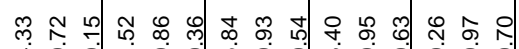
\்

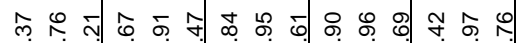
लि 8 :

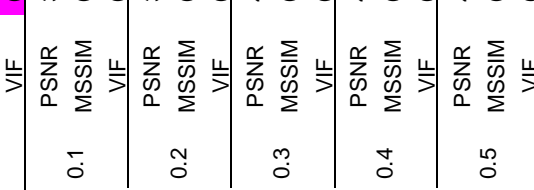

CDF9/7(Lift) + SPIHT 


\section{Appendix B}

Table 2. Variation of PSNR, MSSIM, VIF for satellite Images

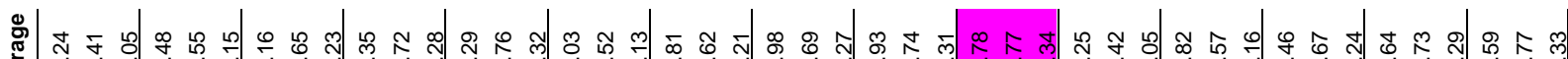
妾

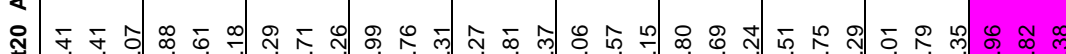
焉

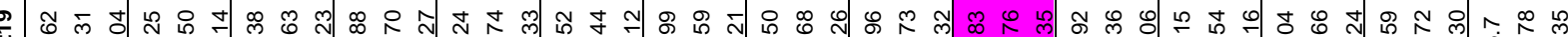
ஸ œ

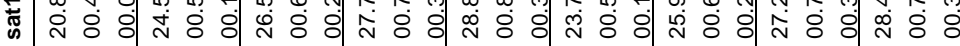

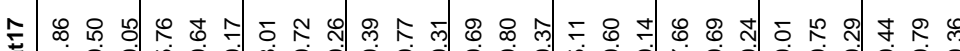

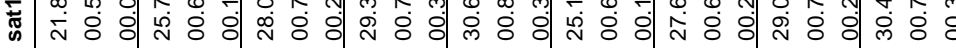

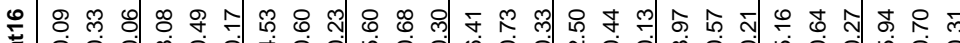
๗

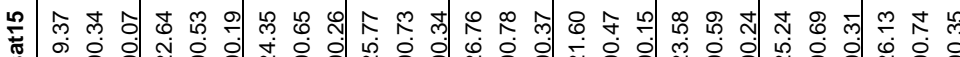
离 Ј 芯

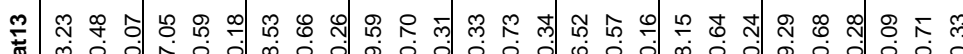

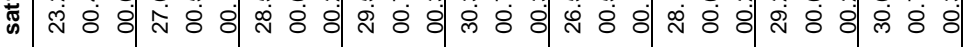

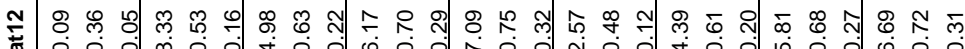
ঊ Е 卷

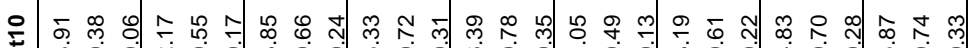
๗ 인 ฌ ๗ œ ๓

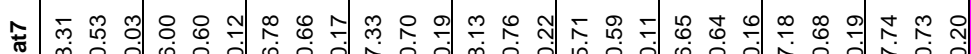
๘

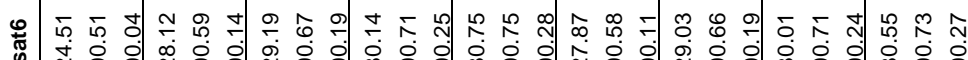

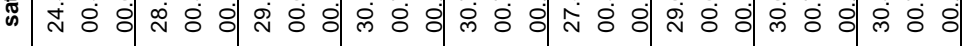

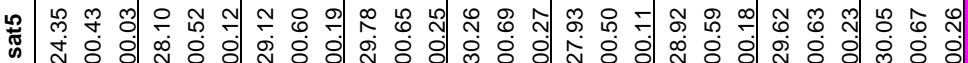
声 $\underset{\infty}{\infty}$ 芯 N

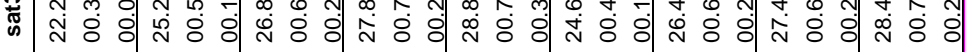

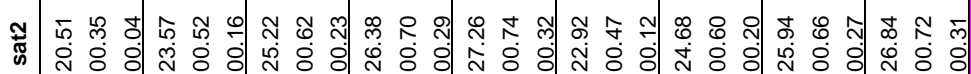

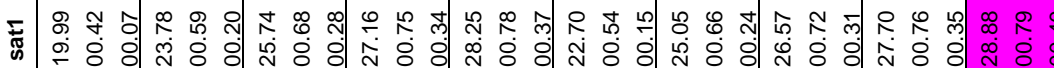

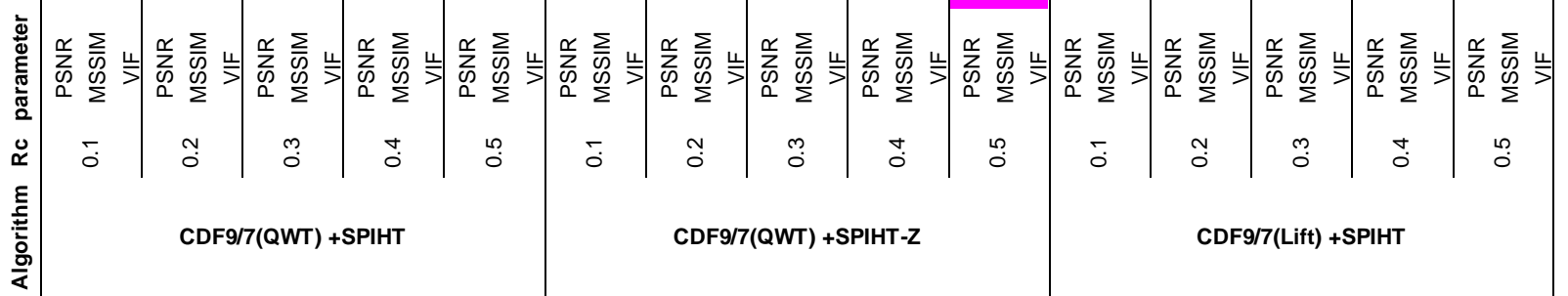




\section{Appendix C}

Table 3. Variation of PSNR, MSSIM, VIF for Natural Images

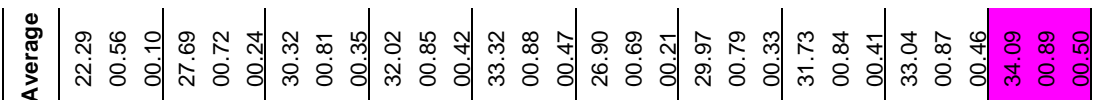

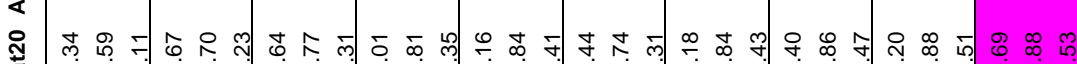

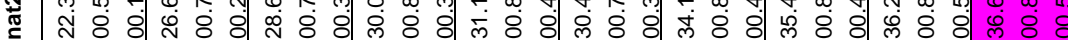

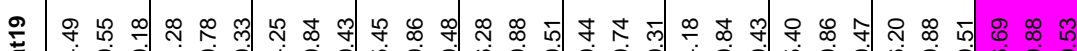

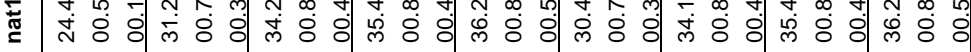

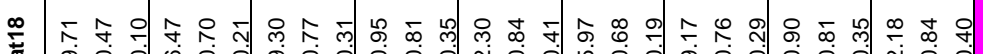

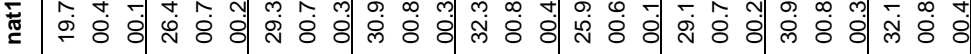

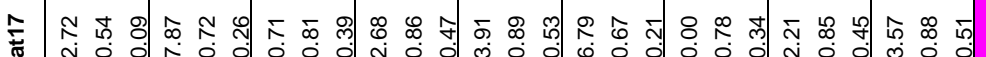

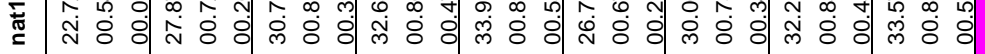

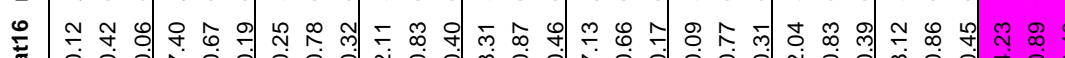

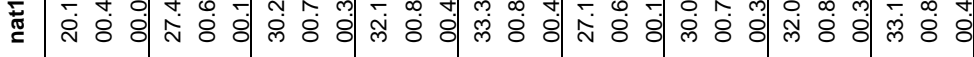

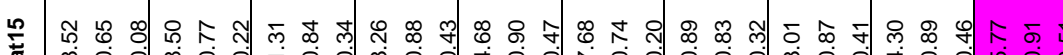

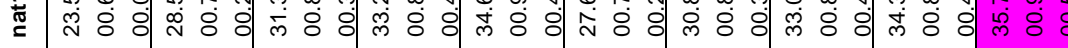

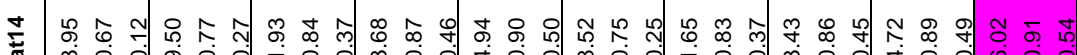

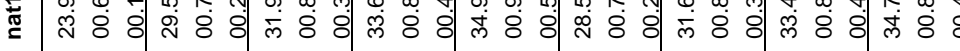

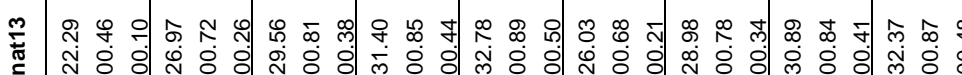

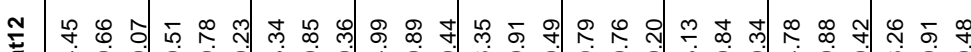

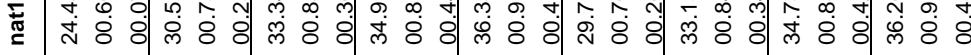

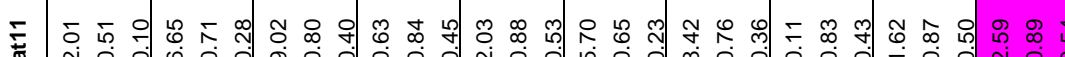

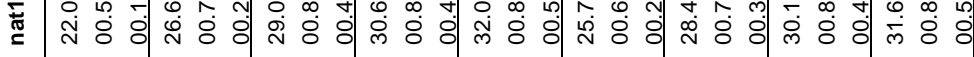

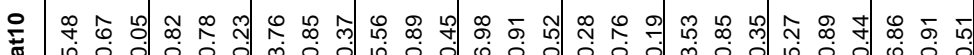

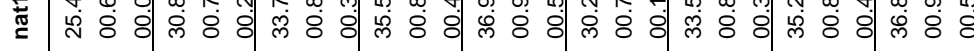

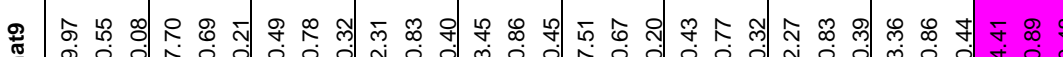

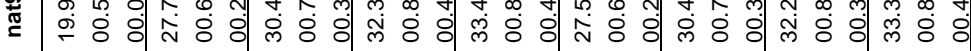

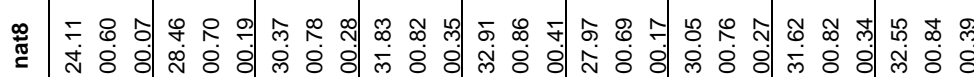

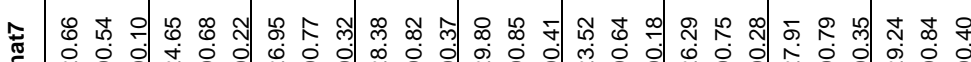

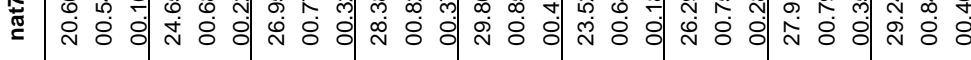

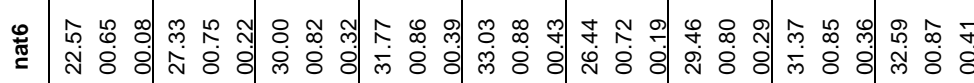

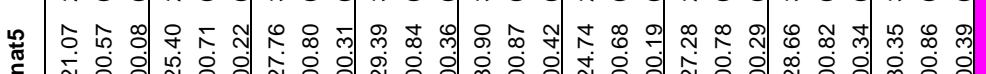

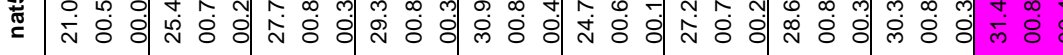
声 品

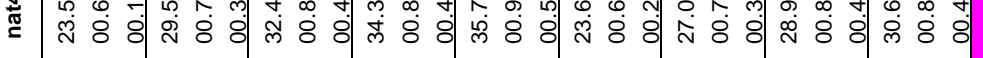

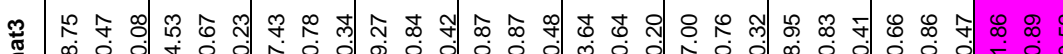
๘

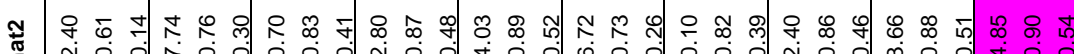

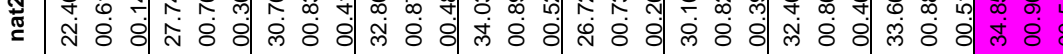

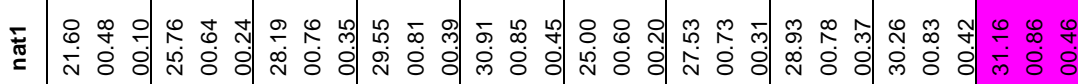

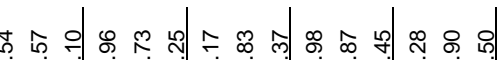

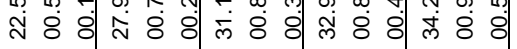

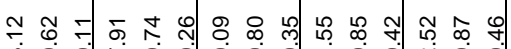

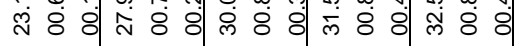
뚜유.

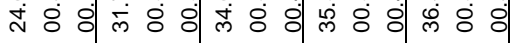

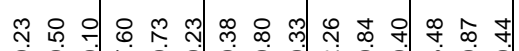

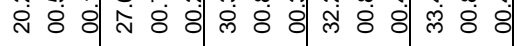

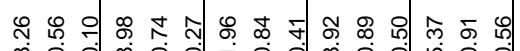

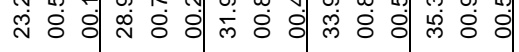

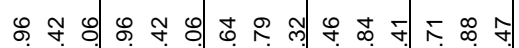

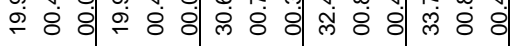
సิ $\because$ ஸे 8 : œ

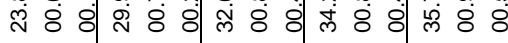

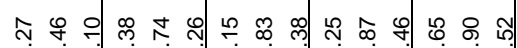

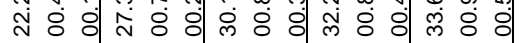

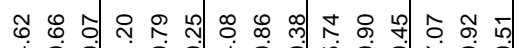

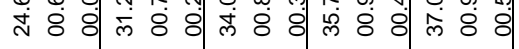
œ ஸे ८

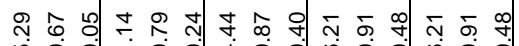
ஸे 8 :

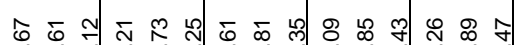

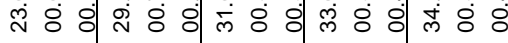

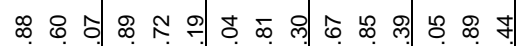

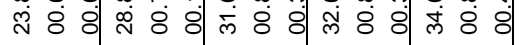

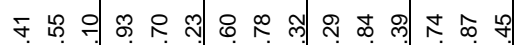
ஸे :

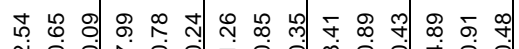

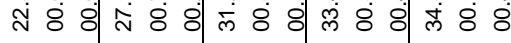

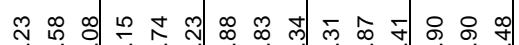

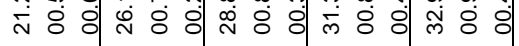

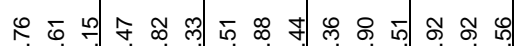

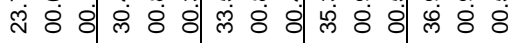

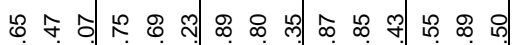

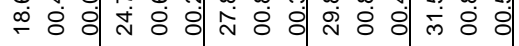

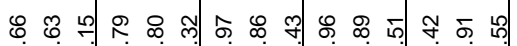

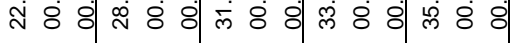

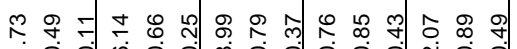

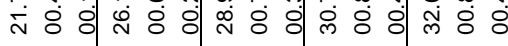

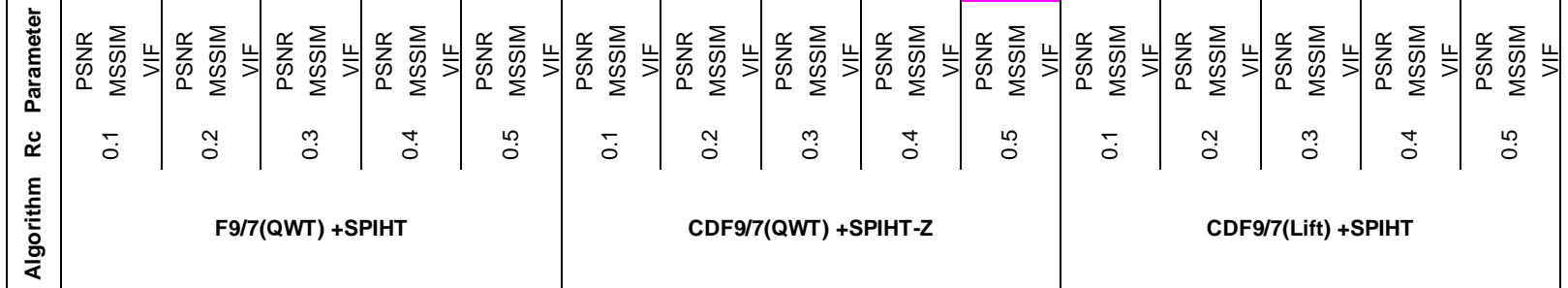




\section{BIOGRAPHIES OF AUTHORS}

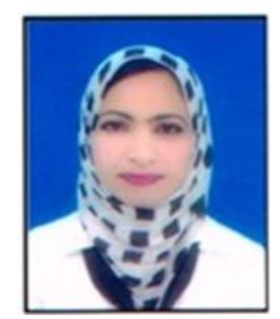

Ismahane Benyahia was born in Bechar, Algeria. she received the dipl. El-Ing from the University of Bechar University, Algeria, in 2009, the Master degree in signals and telecommunication from University of Bechar, Algeria in 2014, and her Doctoral degree Es Science from the University of Bechar, Algeria. Here main interested are Image and video processing, $1 \mathrm{G}$ and $2 \mathrm{G}$ wavelets transform. Correspondance address: Information Processing and Telecommunication Laboratory (LTIT), Tahri Mohammed University, Bechar 08000, Algeria.

E-mail: ismahanelv4@gmail.com

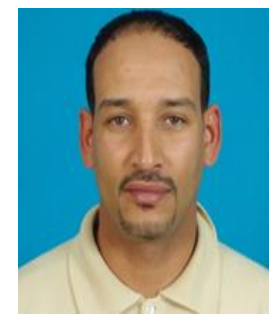

Abdesselam Bassou was born in Bechar, Algeria. He received the Dipl.El.-Ing. Degree from the University of Tlemcen, Algeria in 1997, his Master from the University of Sidi Bel Abbes, Algeria in 2000, and his Doctoral degree Es Science from the University of Sidi Bel Abbes, Algeria in 2006. Actually, He is an Associate Professor at University of Bechar, Algeria. His main interests are digital signal processing, turbo encoding schemes and iterative decoding over fading channels, and channel equalization Correspondance address: Information Processing and Telecommunication Laboratory (LTIT), Tahri Mohammed University, Bechar 08000,Algeria. Email: a.bassou@gmail.com

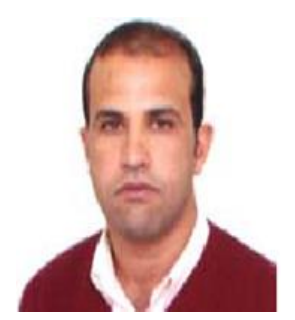

Mohammed Beladgham was born in Tlemcen, Algeria; he received the electrical engineering diploma from university of Tlemcen, Algeria, and then a Master in signals and systems from University of Tlemcen, Algeria and the PhD. degree in Electronics from the University of Tlemcen (Algeria), in 2012. His research interests are Image processing, Medical image compression, wavelets transform and optimal encoder. Correspondence address: Information Processing and Telecommunication Laboratory (LTIT), Tahri Mohammed University, Bechar 08000,Algeria. Email: beladgham.tlm@gmail.com

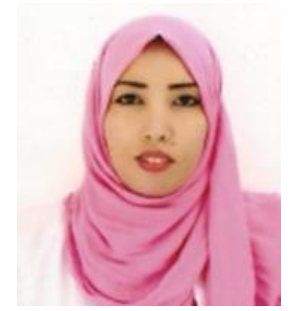

Allaoui Chems El Houda was born in Bechar, Algeria. She received the dipl. El-Ing from the University of Bechar, Algeria, in 2010, the Master degree in signals and telecommunication from University of Bechar, Algeria in 2014. At present, she prepares the doctoral degree Es-science at University of Bechar, Algeria. Her main research areas are image compression and digital signal processing, turbo encoding schemes and iterative decoding over fading channels, and channel equalization. Correspondence address: Information Processing and Telecommunication Laboratory (LTIT), Tahri Mohammed University, Bechar 08000,Algeria. E-mail: chems66@hotmail.com 